\title{
An almost-common path shearographic interferometer using the separation of the polarization states
}

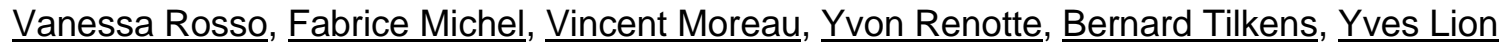
Author Affiliations +

Proceedings Volume 6341, Speckle06: Speckles, From Grains to Flowers; 63411I

(2006) https://doi.org/10.1117/12.695374

Event: Speckle06: Speckles, From Grains to Flowers, 2006, Nimes, France

\section{Abstract}

An original experimental setup for shearography with metrological applications is presented herein. The simplicity and the efficiency of the setup are provided by a shearing device, a prism that separates the TE and TM polarization modes with a coating and a thin glass plate attached on its face. The use of this shearing device enables an in-line and almost-common path configuration for the shearing interferometer, a path that leads to high stability of the interferometer and a low sensitivity to external disturbances. Moreover the sensitivity of the interferometer can be easily adjusted for different applications. The temporal phase shifting method is applied through the use of a liquid crystal variable retarder.

(c) (2006) COPYRIGHT Society of Photo-Optical Instrumentation Engineers (SPIE). Downloading of the abstract is permitted for personal use only.

Citation Download Citation

Vanessa Rosso, Fabrice Michel, Vincent Moreau, Yvon Renotte, Bernard

Tilkens, and Yves Lion "An almost-common path shearographic interferometer using the separation of the polarization states", Proc. SPIE 6341, Speckle06: Speckles, From Grains to Flowers, 63411 (15 September 2006); https://doi.org/10.1117/12.695374 